tion was strengthened by the possibility that it had in some way been imported to our waters through the medium of the mail steamers passing through the Red Sea en route for Australia. However, this does not appear to have originated its occurrence from the fact that specimens exist in the Macleay Collection which must have been obtained prior to the advent of steamers via Suez Canal. Even were this not the case, our insect, to my mind, proves itself sufficiently distinct structurally to separate it from $H$. Hayanus.

When our specimens were first obtained, during April of the present year, a large percentage were discovered in copula ; but observations in regard to the time the eggs were deposited or where laid have up to the present been unavoidably postponed. As the insect occurs in immense numbers ample opportunity is thus afforded for further investigation, ineanwhile I am content to present a preliminary description of the larval and adult forms. In the act of copulation the female carries the male on her back, the latter grasping her round the body with the front legs above the region of the intermediate acetabula.

\title{
NOTE ON THE NIDIFICATION OF EDOLIISOMA TENUIROSTRE.
}

By A. J. NoRTh, F.L.S.

\section{Edolisoma tenuirostre, Jardine.}

Ceblepyris jardinii, Rüppell.

Campephaga jardinii, Gould.

During the latter end of September, 1882, Mr. C. C. L. Talbot observed a pair of these birds building their nest in the angle of a thin forked horizontal branch of an Ironbark (Eucalyptus sp.), about forty feet from the ground, on Collaroy Station, Broad Sound, 556 miles N.W. of Brisbane. A week after, seeing the female sitting on the nest for some length of time, he climbed up to it and found it contained a perfectly fresh egg, which he took (not waiting for the full complement, which is probably two), as the tree was a difficult one to climb, at the same time securing the nest. It was a small and shallow structure composed of wiry grasses securely fastened together with cobwebs, and closely 